\title{
Industry 4.0 and Sustainability
}

\author{
Contributors: , Krzysztof Ejsmont ${ }^{1}$, Bartlomiej Gladysz ${ }^{2}$, ( Aldona Kluczek ${ }^{3}$ \\ 1, Faculty of Production Engineering, Warsaw University of Technology, 02-524 \\ Warsaw, Poland; krzysztof.ejsmont@pw.edu.pl \\ 2, Faculty of Production Engineering, Warsaw University of Technology, 02-524 \\ Warsaw, Poland; bartlomiej.gladysz@pw.edu.pl \\ 3, Faculty of Production Engineering, Warsaw University of Technology, 02-524 \\ Warsaw, Poland; aldona.kluczek@pw.edu.pl
}

Version received: 30 July 2020

check for updates

\begin{abstract}
Sustainability and Industry 4.0 (14.0) are trending concepts used in the literature on industrial processes. Industry 4.0 has been mainly addressed by the current literature from a technological perspective, overlooking sustainability challenges regarding this recent paradigm. The objective of this encyclopedia entry is to evaluate the state of the art of relations between sustainability and 14.0. The goal will be met by (1) mapping and summarizing existing research efforts, (2) identifying research agendas, (3) examining gaps and opportunities for further research. Web of Science, Scopus, and a set of specific keywords were used to select peer-reviewed papers presenting evidence on the relationship between sustainability and 14.0. To achieve this goal, it was decided to use a dynamic methodology called "systematic literature network analysis". This methodology combines a systematic literature review approach with the analysis of bibliographic networks. Selected papers were used to build a reference framework formed by 14.0 technologies and sustainability issues. The encyclopedia entry contributes to the Sustainable Industry 4.0 reference framework with application procedures. It aims to show how 14.0 can support ideas of sustainability. The results showed that apart from a huge contribution to both concepts, many papers do not provide an insight into realization of initiatives to introduce Sustainable Industry 4.0.
\end{abstract}

\section{Introduction}

Industry 4.0 (14.0) as a term and strategic initiative of the German government was introduced in $2011^{[\underline{1}][\underline{2}]}$. Many similar transforming actions towards Industry 4.0 were taken in other developed countries, e.g., US Advanced Manufacturing Partnership, Chinese Made in China, British Smart Factory and others ${ }^{[3]}$. 14.0 and smart manufacturing/factory (which are synonymous) are the natural consequence of the historical developments of computer integrated manufacturing and flexible manufacturing systems ${ }^{[4]}$ from the past decades. However, nowadays, through advanced technologies those ideas of CIM (Computer-integrated manufacturing) and FMS (Flexible manufacturing system) could be further developed and implemented at lower costs. Speaking of Industry 4.0, it should be considered as the applying of flexible automation, cyber-physical systems, (industrial) Internet of Things, sensors, collaborative and cognitive robotics, cloud computing, big data, computer modelling and simulations, additive manufacturing (3D printing) ${ }^{[\underline{5}]}$. This picture clearly shows the technology-driven nature of 14.0 on the one hand. On the other hand, businesses are expecting great benefits:

- economic, e.g., savings through more accurate planning, shorter lead times, increase of energy efficiency;

- environmental, e.g., increase of energy efficiency, decrease of manufacturing scrap waste, etc.;

- social, e.g., increase of safety, more comfortable working environment, etc.

Those benefits are foreseen through emerging possibilities for innovative execution of business processes leading to the creation of a strategic advantage. 
On the other hand, technology-driven nature combined with the relatively early phases of 14.0 technologies lifecycle imply and raise several concerns:

- economic, especially the cost-intensive nature and difficulties with estimation of full financial benefits and economic effectiveness (what could be approached with one of 14.0 technologies: computer simulation modelling);

- environmental, e.g., increase of electro-waste, increase of energy consumption;

- social, e.g., human-robot interaction issues, unemployment threats, privacy issues.

It is clear that 14.0 does not only deliver benefits, but also requires careful consideration of these concerns. Both benefits and concerns could be clearly pictured in the triple bottom line categories: economic, environmental and social. Therefore, the general question arises of what the real impact of 14.0 is on sustainability, both in terms of pros and cons.

Many authors researched phenomena of 14.0, its impacts on economy, society, its barriers and

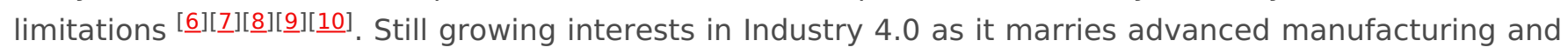
technology seems to be changing the way businesses function. Those changes are deployed to improve the existing production systems by new technologies, offering a better way to organize and manage all processes within manufacturing and services with their logistics and supply chains. It represents the ways in which all emerging capabilities such as blockchain technology, artificial intelligence (Al), robotics and cognitive technologies, augmented and virtual reality might connect with different organizational process assets into unified sustainable production systems $[\underline{[}]$.

Some systems and solutions combine recently emerging new technologies, e.g., cyber-physical systems, but none of technology could solve a problem without the integration with others. All these technologies put together might give opportunities to ${ }^{[5]}$ :

- realize the unique challenges of Industry 4.0;

- create a sustainable industrial environment;

- enhance its impact in the literature and business area.

Industry 4.0 as a contributor to the Sustainable Development Goals (SDGs) ${ }^{[10]}$ builds connectivity between the industry and sustainability by finding a significant relation between their components. The main efforts are, therefore, related to the tools and methods used for the comprehensive analysis of these terms. Much research or state-of-the-art reviews have been already done by researchers, separately for sustainability and Industry 4.0 phenomena[11][12]. A systematic literature review of Industry 4.0 resulting in modelling relationships between sustainability functions and Industry 4.0 was presented in $\left[\underline{13]}\right.$, while ${ }^{[\underline{14}]}$ proposed a new concept of Sustainable Industry 4.0. As intended by the United Nations Sustainable Development Goals ${ }^{[10]}$ for 2030, technological progress is driving the challenge of transition from traditional technology into intelligent machines without limiting the sustainability of the industrial economy. The combination of $\mathrm{Al}$, robotics and other advanced technologies applied across many sectors of economy, e.g., the supply chain, distribution channels, manufacturing, provides a significant impact on the natural environment leading to reduction of pollution, decrease in greenhouse gases emission, decrease in energy consumption and increase in profits, simultaneously. The emergence of Industry 4.0 opens the opportunity of connectivity of technology with resources and skills in terms of sustainability benefits (zero impact-lower cost-social equity). Industry 4.0 can reduce the environmental impact of a product, a process, or a service based on footprint data availability and traceable analysis[15]. Additionally, it helps to leverage a greater efficiency of functions e.g., reduction of resource consumption. Therefore, Industry 4.0 might contribute sustainability to develop digital sustainable operations allowing to meet SDGs goals. Furthermore, increasing development of smart technologies is envisaged as affecting sustainability. The potential of Industry 4.0 is still existing with its unknown impact on other areas like socio-environmental sustainability $[\underline{13]}$ or making opportunities for realizing Industry 4.0 through intelligent systems. 


\section{Sustainable Industry 4.0 framework}

Grounding on cluster analysis depicted in $[\underline{10}]$, the reference framework was constructed (Figure 1).

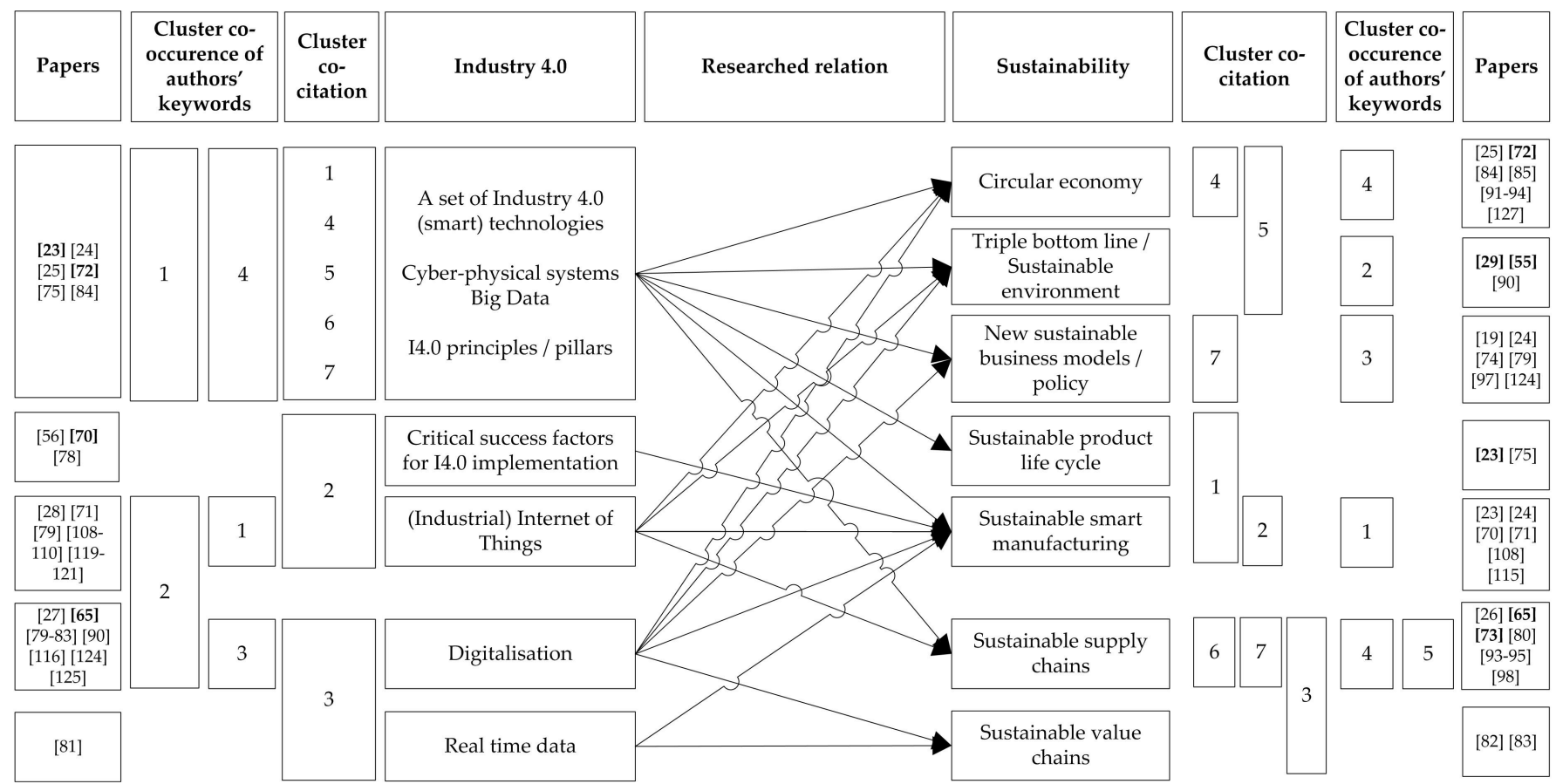

Figure 1. Sustainable Industry 4.0 reference framework based on SLNA from 2012-2019[10].

The goal of this framework is to serve as a kind of manual and guideline for Industry 4.0 applications supporting sustainability principles. The use of framework is based on selection of which sustainability issues are planned to be addressed or defined as critical by an organization. Then, search term is to be found in the framework and next, one may find which 14.0 topics and their relations with the selected sustainability issue were discussed in the literature. There is reference given to the clusters where more details, case studies, best practices could be found. The reverse procedure is applied if one is seeking for possible impacts of planned 14.0 applications on sustainability (Figure 2). After finding the cluster with the topics of interest, one may use GCS values to seek for the most prominent papers in the cluster and start own research from this point. In Figure 1, papers with the highest GCS are listed in bold. The list of papers is in [1으.

How could selected sustainability issues

be supported with I4.0?

Find sustainability issue of interest in the framework

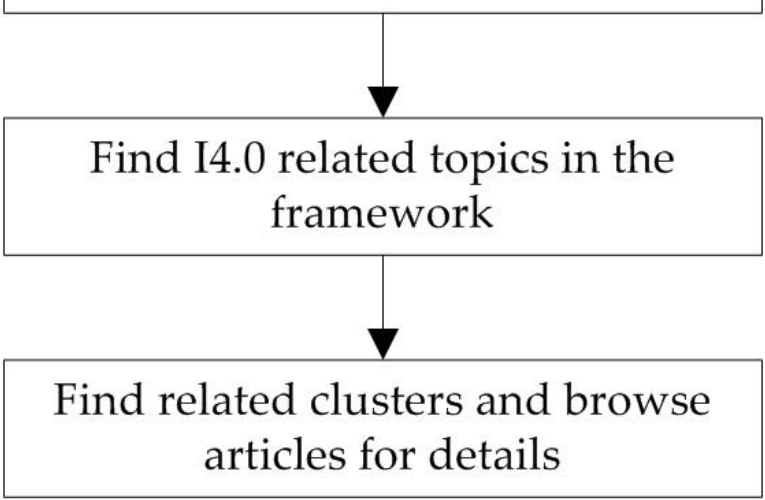

How could planned I4.0 application support sustainability principles

Find planned I4.0 application in the framework

Find sustainability issues impacted by the planed I4.0 application

Find related clusters and browse articles for details 
Figure 2. Sustainable Industry 4.0 reference framework-application procedures ${ }^{[10]}$.

The implication of the framework may result from the industrial use of emerging technologies distributing the sustainable value propositions in an Industry 4.0 environment. The Sustainable Industry 4.0 reference framework is divided into two separate application procedures which depict a logical order of activities of:

- how 14.0 implements selected ideas of sustainability;

- how sustainability principles are supported by planned 14.0 application.

The first procedure starts with finding out sustainability issues of interest and 14.0 related topics in the framework. Using the search, a network composed of linked clusters and articles can be received. In the second procedure a similar sequence of activities was applied. A group of related papers and related clusters that explore how principles are supported by planned 14.0 application may be found using browse.

The application of the sustainable Industry 4.0 reference framework needs to support the development of real-time data-based functions or systems addressing the specific industrial domain sectors. The interrelated elements of the framework provide synergy where processes, Industry 4.0 principles, digital platforms must be interfaced.

The presented framework is of a general nature, therefore it is applicable in a wide variety of organizations. Its strengths are simplicity, clarity and ease of use. However, for specific cases one may need to extend the framework and include details on a lower level, such as guidelines for particular 14.0 technologies or sustainability issues.

\section{Discussion and Future Research Directions}

To develop the roadmap to Industry 4.0 the bibliometric analysis of the selected papers was used instead of the citation method (the most popular in systematic reviews), aiming to minimize any mistakes regarding the accuracy of the information. It prevented the exclusion of essential papers, information and strengthen the results due to use of wide scientific research databases. In the future research, researchers should validate this target sample using the citation method to select relevant papers by searching using query keywords. The advantage of the cross-search tool is to retrieve any important papers cited in the body of literature compared to the previous method relying on the use of the selected academic databases and search terms. The decision of how the method will be applied in the literature research is a hot spot of arguments. The application of large research databases allows to do the exhaustive analysis, on one hand, but on the other hand may lead to misinterpretation of findings.

The bibliometric analysis showed that the topic is very vivid and motivates future research in an investigation of how the technology portfolio of Industry 4.0 could allow to achieve the 17 major goals of sustainable development. Among many challenges and opportunities which are already being examined are understanding of the SDG goals and translating them into unification of indicators/targets across industries in terms of specific functions. It requires to set normative values and then threshold levels for material, energy consumption, etc. It seems that Industry 4.0 has been developing in many industries considering holistic paradigm. Therefore, more focus on separate research on the connectivity of sustainability and Industry 4.0 with benefits from their integration in the fields of interest is needed. In addition, application of the current sustainability assessment tools such as LCA, LCC, SLCA embodied in an advanced IT framework might provide added value.

On the other hand, the development of smart technologies is still growing and leading to dramatic environmental burdens. First, traditional methods for measuring harmful impact are unable to estimate such impact. Second, assessment of the contribution of 14.0 in supporting sustainability is still missing 
[29]. That is why a research gap appears between the sustainability assessment field and technologies represented by a specific sector. A new potential for strengthening this research direction is seen in modelling decision-making mechanisms.

The benefits of combining sustainability with 14.0 could be found. In particular, the paper sketches challenges for Industry 4.0 and its potential in the context of sustainability. By combining sustainability to findings of research on 14.0 which have not been done yet, this current study stream has been complemented. It leads to the development of a new concept of sustainable Industry 4.0 leveraging a greater efficiency of functions or actions through using IT-based technologies (connectivity of technologies with resources, organizational structures, skills, employee empowerment, etc.) A mutual collaboration between efforts of 14.0 and sustainability issues can achieve advantages at the same time: bringing knowledge, economies of scale, fair distribution of cost, experts' experiences, industry-specific data exchange and storage. This high coordination of efforts allows for creating a sustainability-driven business model in a (eco)system. The advantages of this interrelation might be strengthened if the emerging technologies could be compared and assessed considering sustainability dimensions.

For further study, another point could be highlighted to incorporate expert knowledge, experience, and sustainability assessment methods and map them into the Sustainable Industry 4.0 reference framework to provide a synergistic effect.

Based on the research done by the authors answers to each research question were provided:

- RQ1. How applications of Industry 4.0 can contribute to sustainable development?

It enables achieving circular economy paradigms.

It enables sustainable supply chains and value chains.

It enables new sustainable business models.

It enables monitoring of the full product life cycle.

Answering this question, synergy exists between 14.0 and sustainability due to digital technology. By using 14.0-technology affecting sustainability through the responsible, effective use of resources, circular economy can be reached. The concept lying on decentralization of manufacturing which embodied in an IT technology framework was the response to the pressure on changing conventional business models in order to develop new sustainable business models (circular business model). An indispensable way to achieve CE is based on technologies which are often successful when combined with IoT. Industry 4.0 can act as a driver of redesign of traditional supply chains aiming at resource efficiency and circularity.

The 14.0 technologies, e.g., sensors deployed in many machines enable the tracking of production performance and product data over the full product life cycle. In consequence, an analysis of collected data results in productivity improvements.

- RQ2. How Industry 4.0 technologies and tools can be integrated into sustainability practices on a theoretical and practical basis?

Mainly loT, digitization, sensors and big data could be employed to monitor sustainability.

The study confirms that IIOT is an important element of Industry 4.0 and has an impact on sustainability. In future studies, researchers should undoubtedly pay more attention to the importance of IloT in the context of Sustainable Industry 4.0.

Smart technologies of Big Data Analytics, sensors, etc. displaced conventional computer-aided manufacturing industry to deliver tremendous business values or outcomes. On one hand, it provides 
socio-economic values, on the other hand, it creates challenges for doing scientific research on the realtime speed of manufacturing data and data storage.

The application of Industry 4.0 technologies and tools in an efficient way should give opportunities to manage big data (acquisition, extraction, transmission, storage).

The 14.0 technologies can help to reduce both machine operational time and waste thanks to more effective machine and resources utilization consequently ensuring cost-effective operation. Sensors used in production allow to gather a machine's status data to analyze load of machines, reducing downtime and protecting products against unexpected failures which have a great impact on product quality.

- RQ3. What are the main approaches/methodologies/frameworks/tools that should be considered for integrating Industry 4.0 with sustainable development?

Critical success factors were discussed in the literature. Regarding the third question, coalesced with the second one, the encyclopedia entry addressed some of the critical success factors for the use of IoT, e.g., transparency, resource efficiency, creating knowledge through digitalization that impacts the achievement of sustainability. The identified factors, which interact with IoT system, sensors, etc., contribute to SDGs. It would also support Sustainable Industry 4.0 reference framework implementation in manufacturing. On the other hand, some factors might hinder the readiness to implement 4.0 technology. By incorporation of digitalization as a binder of the factors, sustainability performance in the production environment could be measured and monitored, tracking data in real time. In this sense, it leads to an increase in resource efficiency, reducing inefficient work, revealing costs treated as inefficient when using the latest technology. Thanks to the capturing of massive data, production can be now deeply analyzed and reliable information about production efficiency is still available and up-todate.

Effective use of critical success factors and approaches pertaining to Industry 4.0 allow the fostering of sustainability in smart data-driven manufacturing.

\section{References}

1. Kagermann, H.; Lukas, W.; Wahlster, W. Industrie 4.0-Mitdem Internet er Dinge auf dem Wegzur 4. Industriellen Revolution [Industry 4.0: With the Internet of Things towards 4th Industrial Revolution]. VDI nachrichten, 2011, 132011. Available online: https://www.dfki.de/fileadmin/user_upload/DFKI/Medien/News_Media/Presse/PresseHighlights/vdinach2011a13-ind4.0-Internet-Dinge.pdf (accessed on 19 June 2020).

2. Kagermann, H.; Wahlster, W.; Helbig, J. Recommendations for Implementing the Strategic Initiative Industrie 4.0: Final Report of the Industrie 4.0 Working Group. National Academy of Science and Engineering. 2013. Available online: https://www.din.de/blob/76902/e8cac883f42bf28536e7e8165993f1fd/recommendations-for-implementingindustry-4-0-data.pdf (accessed on 30 March 2020).

3. Kumar, S.; Suhaib, M.; Asjad, M.; Industry 4.0: Complex, disruptive, but inevitable. Manag. Prod. Eng. Rev. 2020, 11, 43-51.

4. Scheer, A.W.; C.I.M. Computer Integrated Manufacturing: Towards the factory of the future. Long Range Planning 1992, 25, 128, 10.1016/0024-6301(92)90351-2.

5. Xu, L.D.; Xu, E.L.; Li, L.; Industry 4.0: State of the art and future trends. Int. J. Prod. Res. 2018, 56, $2941-2962$.

6. Adamik, A. SMEs on the way to SMART World of Industry 4.0. In Eurasian Business Perspectives, Proceedings of the 25th Eurasia Business and Economics Society Conference; Huseyin Bilgin, M., Danis, H., Demir, E., Ucal, M.Ş., Eds.; Springer Nature Switzerland AG: Cham, Switzerland, 2020; pp. 139-156.

7. Basl, J. Pilot study of readiness of czech companies to implement the principles of Industry 4.0. Manag. Prod. Eng. Rev. 2017, 8, 3-8.

8. Kamble, S.S.; Gunasekaran, A.; Sharma, R. Analysis of the driving and dependence power of barriers to adopt industry 4.0 in Indian manufacturing industry. Comput Ind. 2018, 101, 107-119.

9. Lee, S.M.; Trimi, S. Innovation for creating a smart future. J. Innov. Knowl. 2018, 3, 1-8.

10. Krzysztof Ejsmont; Bartlomiej Gladysz; Aldona Kluczek; Impact of Industry 4.0 on Sustainability-Bibliometric Literature Review. Sustainability 2020, 12, 5650, 10.3390/su12145650.

11. Franciosi, C.; lung, B.; Miranda, S.; Riemma, S. Maintenance for sustainability in the Industry 4.0 context: A scoping 
literature review. IFAC-PapersOnLine 2018, 51, 903-908.

12. Bonilla, S.H.; Silva, H.R.O.; da Silva, M.T.; Gonçalves, R.F.; Sacomano, J.B. Industry 4.0 and sustainability implications: A scenario-based analysis of the impacts and challenges. Sustainability 2018, 10, 3740.

13. Morteza Ghobakhloo; The future of manufacturing industry: a strategic roadmap toward Industry 4.0. Journal of Manufacturing Technology Management 2018, 29, 910-936, 10.1108/jmtm-02-2018-0057.

14. Sachin S. Kamble; Angappa Gunasekaran; Shradha Ashok Gawankar; Sustainable Industry 4.0 framework: A systematic literature review identifying the current trends and future perspectives. Process Safety and Environmental Protection 2018, 117, 408-425, 10.1016/j.psep.2018.05.009.

15. Bernd Peukert; Stephan Benecke; Janire Clavell; Sabrina Neugebauer; Nils F. Nissen; Eckart UhImann; Klaus-Dieter Lang; Matthias Finkbeiner; Addressing Sustainability and Flexibility in Manufacturing Via Smart Modular Machine Tool Frames to Support Sustainable Value Creation. Procedia CIRP 2015, 29, 514-519, 10.1016/j.procir.2015.02.181.

16. Bernd Peukert; Stephan Benecke; Janire Clavell; Sabrina Neugebauer; Nils F. Nissen; Eckart UhImann; Klaus-Dieter Lang; Matthias Finkbeiner; Addressing Sustainability and Flexibility in Manufacturing Via Smart Modular Machine Tool Frames to Support Sustainable Value Creation. Procedia CIRP 2015, 29, 514-519, 10.1016/j.procir.2015.02.181.

\section{Keywords}

industry 4.0; sustainability; literature review; fourth industrial revolution; bibliometrics 